\title{
Narratives of Adoption
}

\author{
Andrea Rucska*, Anna Perge \\ Faculty of Health, University of Miskolc, Hungary
}

Received April 14, 2020; Revised May 26, 2020; Accepted June 16, 2020

Copyright $(02020$ by authors, all rights reserved. Authors agree that this article remains permanently open access under the terms of the Creative Commons Attribution License 4.0 International License

\begin{abstract}
In Hungary, the rate of adoption is much lower compared to the number of children living in institutional care. Adoption provides an opportunity for ceasing the negative factors in the personality development of children in institutional care and reaches a better quality of life. The aim of the research is to reveal whether children's age and the time of adoption affect the development of personality, regarding the attachment relationship between children and parents. Additionally, we would like to map how the personality of adopted children changes after getting to a family, and what the characteristics of its development are. For the retrospective study, an interview method was used, it happened by the adopting parents in case of all the ten included families. The interviews covered the following subjects: the reason for adoption, thoughts related to children, uncertainty factors in connection with adoption, acquaintance periods, the events of the family's home and the difficulties of the family socialization process. The interviews were analyzed by content analysis. The possibility of adoption came up in most of the families included in the research after medical interventions and the acceptance of infertility. The incorrigible and severe health damage of the child was a reason for exclusion in association with the child to be adopted. Four couples had no criteria about the origin. All families reported about uncertainty and fear before adoption. In the moment of adoption, the youngest children were newborns, and the oldest child was six and a half years old when getting to the adopting family. In respect of the examined families, the interval between the submission of the application and getting to the family was between two months and two and a half years. The initial difficulties were greatly different in the cases of newborns and children adopted to an older age. Parents defined the first six weeks as the hardest in case of newborns. The support of the family's background and friends after adoption could be detected in case of eight families, two families experienced the rejection of the grandparents. It is indisputable that adoption as early as possible is the ideal for children. If we know the case history, in case of experiencing a crisis,
\end{abstract}

the arising problems can be treated effectively only by teamwork with the parents and the representatives of related professions. Children have the right to health, a healthy lifestyle, and we should always strive to create optimal conditions.

Keywords Adoption, Childhood, Development, Family, Related Professions

\section{Introduction}

Hungary is a $93030 \mathrm{~km}^{2}$ area in Central Europe, in the middle of the Pannonian (Carpathian) Basin. The population is 9.7 million people and its capital city is Budapest. ${ }^{1}$ In Hungary, the number of children living in institutional care is quite high, while the total number of adoptions is quite $\operatorname{low}^{2}$ [1]. In 2018, 21210 infants $^{3}$ (under the age of 18) received child protection specialist care, the guardianship authority permitted the adoption of only 1000 children in the same year ${ }^{4}$, while 2855 families were waiting at the same time. Children in institutional care often experienced the feeling of abandonment and isolation and the lack of emotional stability, which negatively influences their personality development [2]. Mental injuries caused by the lack of trust can be found in both early regulation disorders and later addictions and psychotic conditions [21]. Adoption provides an opportunity for children living in institutions to get into a harmonious family and for balanced personality development. The child's period spent without a family in a foster home makes it extremely difficult or it even prevents the process of developing a healthy attachment. These factors strongly influence the child's attachment and the development of trust, since these can occur in children parented in an institution, and in case of

\footnotetext{
${ }^{1}$ Based on the data of the Hungarian Central Statistical Office.

2 According to the guardianship authority's data, 735 adoptions were permitted in 2010, 726 in 2013 and 1000 in 2018 in Hungary.

5219 of them is between the age of 0 and 5 .

${ }^{4}$ Based on the data of www.ksh.hu
} 
antisocial, extreme parenting, the often change of the nursing person and the repetitive placement at families and moving. The reactive bonding disorder in these children is characterized by alienation and shyness not reacting for relaxation. Age-appropriate attachment characteristics to the parents or nurses cannot be recognized, their social reactivity is poor. Uninhibited bonding disorder is the disorder of social relationships that can develop in the first five years of life. Around the age of 2 , it is characterized by the clamber and clinging on the nurse and bonding behavior without selection. At the age of 4 , it is replaced by the endeavor for rising attention. The child does not keep the distance from adults, and he/she is too friendly to them without selection [22]. In these cases, adoptive parents have a great responsibility to help the child through this difficult initial period and, despite the period spent separated, to create a harmonious relationship between the adopting and the adopted party, since it is such a determinative socialization process that can provide the healthy personality development for children [3].

The number of children waiting for adoption is significantly higher than the number of potential adoptive parents. Children to be adopted often have a disability, a long-term illness, or they are simply "over-aged" for the adoptive, since these children are often older than 10 years old, and the chances for adoption greatly depend on the children's age ${ }^{5}$ [4].

In the last years, more legal regulations have happened ${ }^{6}$ by which the adoption process has undergone major changes and it is regulated by the Government Regulation of 2014. ${ }^{7}$ The regulation enables adoptive parents to meet the child immediately after birth in the hospital. This is especially favorable for both the newborn baby and the prospective parents, since it provides the opportunity for the parents to experience everything that would be natural at birth, and this process helps the parent candidates to prepare for the parenthood, to become a mother and a father. Additionally, it regulates that the adoption of infants can be stopped only in special cases. The introduction of obligatory monitoring of the adoptive is also an essential element of regulation [5].

Both children and parents have to face difficulties during the process of adoption. These difficulties determine the successful outcome of the adoption and the child's personality development [6]. In case of the adopted children, the greatest problem is that they spent a part of their lives in foster homes or under institutional circumstances, without loving parents. The outcome of the adoption process is determined by the child's age and his/her experiences before the adoption. The lack of a

\footnotetext{
5 The child's chance for adoption strongly decreases after the age of 3 .

${ }^{6}$ Adoption was regulated in almost every year after 2011 (in 2011, 2013, 2014, 2018 and 2020)

Government Decree No. 72/2014 (III.13) on the activity of non-profit organizations promoting and monitoring adoption and the authorization of their operation
}

mother is also determinative which influences negatively the children's psychic function, causing depression and hospitalism [7].

The secret of the success of the adoption is whether the parent candidates are able to or they are prepared to develop a loving parent-child relationship with a child who is biologically not bound to them. In case of most couples parenting children of their own blood, fetal communication during pregnancy and the experience of labor instinctively prepares for the parent role, while this is not possible for adoptive parents. Adoptive couples can often expect less help and support from their closer families and the wider environment, so this life period of adoptive parents is much harder [3].

Before adoption, the prospective parents often undergo several unsuccessful medical examinations and interventions that indispose the families both medically and psychically. Therefore, it is very important to ensure that the adoptive parents should be prepared for the adoption both mentally and medically to raise other parents' child, because they can provide an emotionally stable and trustful atmosphere for the child only this way [2]. The length of the adoption process is a serious problem. It could take a long time, even years and the arrival of a child is uncertain. So, parents are often anxious, and they may reflect this negative feeling unconsciously to the child [2].

The aim of attachment is to provide a positive emotional background for the child which could help him/her discover the surrounding environment [8]. Attachment can be interpreted as such a process, fact or condition where bonding, to be related to something and an emotional relationship occurs [9]. The infant-parent attachment may become difficult because of the parents' doubts and criteria related to the child, which often does not match with the child's personality. A further complicating factor is that the harmonious family atmosphere does not develop immediately after the child's arrival. After the institutional period, experiencing changes and new environments mean great challenges for the child as well, and the acclimation process can take a shorter or longer time for the children to be able to adapt to the new environment, learn to trust and feel safe in their new microenvironment. The socialization process might also be complicated by the fact that different health damages are more often in children living in public care. These factors and circumstances may arise in anxiety and doubtfulness in adoptive parents [2].

Regarding the difficulties, in connection with the parenting of the child, it is essential to mention the knowledge of the fact of adoption that is subservient to be talked about with the child even from the beginnings [10].

\section{Materials and Methods}

\subsection{The Aim of the Research}

The aim of the research is to reveal whether the age and 
the time of adoption have significance from the aspect of the children's personality development due to the development of bonding relationships between children and parents. The aim of our research is to discover the personality development process of the adopted children after getting to a family.

\subsection{Materials and Methods}

For the retrospective study, owning the permission of the ethical committee ${ }^{8}$, an interview method was used, the sample was selected by snowball sampling method. In case of the selected 10 families, the interviews were carried out without the involvement of children in all cases. The families live in the highly disadvantaged region of North-Hungary. The included families were suggested by the visited and firstly interviewed families, and they mediated the next ones. Not all the visited families undertook the participation in the investigation. The recorded data are anonymous.

The interviews covered the following topics: the reason for adoption, the thoughts about the child, uncertainties in connection with the adoption, the acquaintance periods, and then the events of the families' homes and the difficulties of family socialization. The interviews were evaluated by content analysis.

\section{Results}

\subsection{Antecedents of Adoption}

The reasons for adoption were quite different. Besides health damages, we could find mental problems, psychic loadedness and depression as well. Among the families included, six families had undergone medical interventions, hardships and numerous in vitro fertilization procedures, and the possibility of adoption came up after accepting infertility.

\subsection{Criteria Related to the Children}

The prospective adoptive parents defined several different criteria about the child to be adopted, however, some identical criteria could be detected. All the families refused children with special needs, including incorrigible serious health damages, such as mental health problems and disability. In the contrary, the corrigible minor health problems, such as squint, were no reasons for refusal. In case of four families, children's ethnic background was defined as a criterion, which included the Roma origin of the child. The reason for this is the significant prejudice of the Hungarian society against the Romani minority. The

\footnotetext{
${ }^{8}$ Based on the Decree No. 20/2002 (V.9) of the Ministry of Health, authorized by the Regional/Institutional Scientific and Research Ethical Committee.
}

minority has not any positive values for the non-gypsy majority (as the majority thinks) that would compensate for this negative prejudice. One reason for this is that most of them are highly disadvantaged and they have a low social status that is mostly manifested in their deviant lifestyle. Poverty and unemployment cause that a part of the society reflects its emotions to some of the minorities [23].

Two families reported that if any information is available about the child's origin, they would not adopt a child with a Romani background. In case of four families, the origin was not an important factor, they would adopt a child from a minority as well.

\subsection{The Waiting Period}

The interval between the submission of the application and the possibility for adoption, the signal of the authority about the child's arrival was quite variable. Five families were informed in 1 year and 8 months and $2-2.5$ years after the submission, one family waited only 6 months, while another of them was informed about the viewability of the child in two months. Three children lived in their own families before the adoption, and in their cases, two months passed after the submission of their application.

In the examined sample, the criteria defined by the adoptive parents influenced the interval of the adoption. The process can take a few months, or several years as well. Those examined families, who defined fewer criteria and were more tolerant, became adoptive parents earlier (Table $1)$.

Table 1. Criteria in the highlight of the waiting period

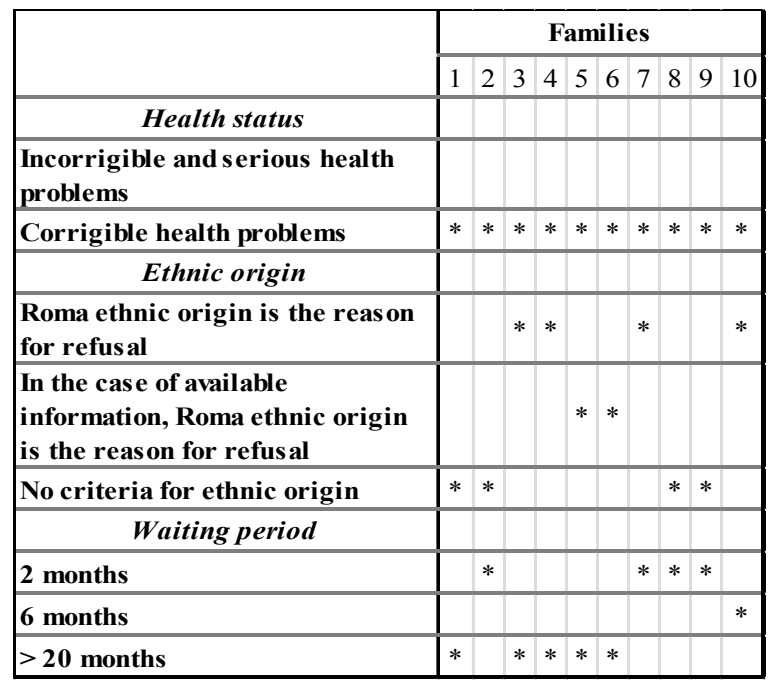

\subsection{Uncertainty Factors before the Adoption}

All families reported feeling uncertainty and fear before the adoption. Some of them feared that after childhood, the child will turn away from the adoptive parents, he/she will not consider them as real parents. More parents had doubts about the infant-parent attachment, whether they will be able to love the adopted child, as their own, and this feeling 
will be mutual. However, these initial negative feelings passed shortly. One parent defined that her thoughts about adoption oscillated at first. She listened to mothers on the street or bus and thought whether she will be able to love someone's child as her own. Sometimes she thought that every child can be loved, and she wanted to be a mother as well. This family defined their doubts about the initial difficulties of adoption in the habituation period. Two families were afraid of how their environment will react to the adoption.

\subsection{The Background of the Child}

The children had different backgrounds and ages, which also affected the length of the adoption process. Three children were living with their biological families; however, the lifestyle of the biological parents seriously endangered the children's healthy development. One lived at foster parents, four of them were adopted in one week after their birth. Two children spent their lives in an orphanage before the adoption.

\subsection{The Children's Age in the Moment of Adoption}

Four children were adopted within one week after birth, one was 15 months old, one was 1 year old, and one was 2 years old. The children living in their own families before the adoption were 4,1 and 6.5 years old.

\subsection{In the Family Home after Adoption}

The adoption is also a challenge for children; they experience several difficulties, new situations in the new environment. Regulation disorders could be experienced in three cases after arriving at home, in these cases the children were unreasonably restless in the nights and sometimes in the days, they were crying. After arriving home, excessive crying, restlessness and sleeping disorders could be experienced in two newborn children, they were almost inconsolable, and a 4-year-old girl had similar behavior regulation disorder as well. One case of them was considered to be caused by the newborn's omphalocele, the parents told that the doctor suggested avoiding all positions that would lead to crying in order to avoid strain.

The initial difficulties differed in newborn children and the lately adopted, older children. In case of the newborn children, the first six weeks were reported to be the most difficult period for the adoptive parents, taking also into account that the birth mother can consider the adoption in the first six weeks. ${ }^{9}$ This is a quite great challenge for the adopting parents, because it makes it more difficult to create a strong emotional relationship, since it is possible that they have to give back the child for the biological

\footnotetext{
${ }^{9}$ Based on Act V of 2013 on the Civil Code, the parent can withdraw his/her permission notice in both cases in six weeks after the child's birth, for the sake of the child's parenting by a parent or another relative.
}

family. The first month of the post-institutionalization period was also a difficult period for two other, older children. The adoptive parents reported that children were shy and distrustful in the new environment; furthermore, they never smiled in the first month. The parents thought that the child could not accept the new environment, but the child started to dissolve after a month. However, the adoptive parents thought that consistency and regular schedule facilitated children's integration into their new families.

Three children had habits before being adopted that could be left after it. One baby could be fed by a spoon after the arrival of the family. This child was not willing to open her mouth for a spoon or a cup in the foster home. According to the nurses and the parents, the girl would have desired physical contact and wanted to make the feeding time in lap longer, as she accepted food from a bottle. After her arrival to the family, she received attention and loving care for which she was able to use cutlery and cups.

In two cases, the problems were caused by socio-cultural deficiencies, the extremely few stimuli and bad social conditions, the blood parents could not provide necessary eating for the children, so they starved. After being adopted, one child could not restrain eating, and the result of the eating rushes was often vomiting that was long-lasting, even despite parental relaxation. One child urinated in the bed and tore the sheets regularly in the period of arrival.

In three cases, the children arrived at their families with different level deficiencies in social competence. Two children were not aware of basic hygiene rules, such as daily bathing or showering, using toilets. One child, who was 2 years old, was able to bath, dress, eat alone, he/she did not require any help, but he/she was extremely afraid of the sight of the bathtub that he/she did not dare to use. This fear often manifested in hysterical crying. This suggested that the child did not know this bathroom facility. The children had basic deficiencies in trivial fields of life as well, they could not use the toilet, daily toiletries or changing underwear was not natural for them. Moreover, these children were surprised that the bathroom is the part of the apartment, and they have their own beds, blankets, and the apartment is well-heated in winter. The adoptive parents described this initial period as a difficult socialization process when they had to teach the children for simple trivial things. There were children who could catch up only in a half year by long and exhausting work. Two children were surprised at arrival because their new home was warm, and there was electricity in the apartment.

Many adopted children feel uncertainty in the new environment and different initial regulation disorders are almost always detectable. Almost all the children desired physical closure, seven of them directly searched for the adopting mother, two of them clutched to the mother's leg for a long time after the arrival and the mother came closer this way. 
Three children regularly followed the adoptive mother in the apartment, and in a case of a child, the one-meter-distance from the adoptive mother during walking resulted in fear, which was accompanied by a panic attack and hysterical choking crying. These attacks ceased soon as the child was picked up, relaxed and stroked.

The adoptive parents believed that children had the right to know their family background. In all cases, the adoptive parents mentioned that the infant-parent relationship is based on trust and honesty. Only one family thought that they would not talk about the fact of adoption with their child.

\subsection{Children's Possible Harms due to Adoption}

Children are known to be adopted often experienced more severe prejudice and insults in the school community. In those cases, where the school community did not know the child's family background, no abuse could be experienced.

\subsection{The Attitude of the Family and the Closer Environment to the Adoption}

The support of the family background and friends could be detected in eight families after the adoption. Although, in two families, the grandmother's rejection could be experienced. In both cases, the grandmothers treated the adopted children differently, while they were devoted, kind and forgiving with their biological grandchildren.

\section{Discussion}

Based on Hungarian surveys, the rate of adoption is much lower compared to the number of children living in institutional care, since the demands of the adopting families and the children's personality, health status and origin do not always meet [1]. It should be mentioned that, according to the Hungarian laws, not the children to be adopted are searching for families, but the child protecting authority searches for families for the children where their harmonious physical and mental development will be ensured.

Therefore, regarding adoption, it is necessary to talk about the situation of children with special needs [16]. Based on our results, all families excluded the option to adopt a child with an incorrigible or serious health damage. In our study, the range of families adopting children with minor health problems occurred, but they told that they clearly refuse children with special needs. In order to ensure that a higher percentage of children with special needs could be placed into adoptive families, it would be necessary to encourage the submission of recommendations by experts' opinions based on different professional considerations [16]. Among the criteria against the children, there was a correlation between the children's ethnic origin and the waiting period. In most cases, those families who refused the opportunity to adopt a child with Roma background had to wait several months or more than a year. The stereotypes and misconceptions in the Hungarian society revealed by research may feed the stigmatization of the adoptive families, and these prejudices are particularly evident in case of inter-ethnic adoptions. In these cases, the adopting families have to face both their general concepts about adoption and the general anti-Roma feelings as well [17]. In our study, almost 50 percent of the interviewed families defined criteria for Roma ethnic origin, probably due to the public perception of parents adopting a Roma child.

Both the permanent health damages and the Roma background made the placement of adoptable children more difficult. Families were ready to adopt children with minor, corrigible health problems, but possible behavioral disorders or developmental disorders affected more negatively the children's chances. Based on the experiences of professionals working in the child protection system, the professionals nursing and caring for children before the adoption, even the racial features influence negatively a child's chances for adoption, however, no information is registered about it in the database, so the authors can only carefully suggest a correlation between the children having Roma racial characteristics and the adoption tendency.

In our research, the eldest child was 6 and a half years old at the time of adoption, therefore, all the interviewed families could use the Health Visitor Service ${ }^{10}$ [15] which has been successfully operating in Hungary for more than a hundred years ago [14] and it is an important support for parents in the post-institutional period. Although, the initial difficulties were different among the adoptive parents, we can ascertain that parents felt uncertainties and fear before the adoption. To solve these problems, the most effective way is to ask for help from a professional, so, it could be a support to create a close relationship with the territorially competent health visitor and have effective communication with her. The health visitor could help parents to overcome their doubts, give advice and provide reliable, constant and individual care for both parents and children during the difficult initial period.

The bright side and the difficulties of adoption are experienced by both participants. The adoption process is a quite significant and stressful period for both parents and children; however, it gives the chance for both parties for having a meaningful life filled with care and love. The adopted child gets a chance for a safe start of life and the adoptive has the possibility to experience the parent role. The meeting of the roles has difficulties, but the earlier the child is adopted, his/her personality suffers from less harm,

\footnotetext{
${ }^{10}$ The health visitor service operating in the country is a part of primary care and performed mostly in the families' homes. The health visitor accompanies the child's life from the mother's pregnancy to the age of 18 .
} 
it is easier to develop a bond and a harmonious family background [6]. Regarding the development of attachment, the initial difficulties were quite different in the examined group, but all families reported some. While the families adopting newborns reported the first six weeks to be the most difficult, families adopting an older child spent even a half year to have the child acclimatized to the new environment, norms and having new habits. The affected families described this socializing period as extremely hard.

The development of hospitalization often occurs in case of children growing up in a foster home [11], so it is important to strive for placing children to loving families as early as possible to prevent the development of personality deformity. At the beginning of the hospitalization period, many children become irritated, crying and weight gain often decreases. Further lack of the mother leads to emotional bleakness, children can become apathetic, insensitive to external stimuli and prone to somatic illnesses [12]. From the clinical aspect, regulation disorders are the forms of psychic or psycho-somatic diseases of babyhood and infancy. Their complex cause background includes biological characteristics, the parents' unfavorable psychosocial conditions, the lack of support of their social environment or its inappropriate method [21]. The mother's physical closure and protecting love are indispensable for the children's optimal emotional development [12]. In the researched sample, the lack of the mother's physical contact and common crying caused by it could be experienced in more cases. After adoption, these children craved for the presence of the adoptive parents, in seven cases, they had an explicit attachment to the adoptive mother, and two children showed excessive affection (they constantly clung to the mother's feet). Although, some of them lived in foster homes, foster parents and some of them were older, adoptive parents perceived difficulties rather in social and emotional development than in children's attachment. According to Johnson [13], adoption is a successful service for children and parents. The results of adoption are more beneficial for children than any social programs. Based on our results, we have to agree.

The adoptive parents can often rely on less help from the closest family and friends, so, the initial phase could be difficult for them [3]. In eight cases, adoptive parents involved in the research could count on the help of the family's background and friends, in the contrary, the grandparents refused the adopted child in two cases.

Children were often insulted by other children in the school, when the community was informed about the fact of adoption. Where the fact of adoption was not known, negative events could not be experienced. The question comes up, whether we could protect children, if we withhold the fact of adoption, or it is obvious that they have the right to know the truth about their origin.

Further questions arise, for example the most ideal age or period for adoption and the consequences of a later adoption and temporary solutions, such as foster families or foster homes. The results of Batki [18] supported the assumption that children adopted from institutional care have less developed emotion regulation skills or they are less effective in using these skills, so their social competencies need a lot of development. The events experienced before the adoption is another important issue. Within the framework of primary health care, so during the GP's and health visitor's care, the physical, psychological, mental, motoric, social development, organoleptic examinations, speech development and possible developmental differences are examined and documented from birth. In case of a crisis, knowing the case history, the effective management of the problems can be accomplished by the teamwork of parents and related professionals, including doctors, health visitors, kindergarten teachers or, if it is necessary, psychologists (and everybody who serves the children's right to a healthy life).

\section{Conclusions}

Many of the prospective adoptive parents define criteria about both the health status and the ethnic origin, which significantly influences the interval of the adoption procedure. All families felt uncertainty and fear before the adoption. In Hungary, the health visitor service helps the parents to overcome their doubts during the difficult initial period. Regarding the development of attachment and mental harm, the earlier age at adoption showed more favorable results. In most cases, the adoption was supported by the microenvironment. However, children often experienced prejudice in the school community, when adoption was a known fact.

The arising issues would justify wider examinations in which longer observations would be necessary along some dimensions. Similarly, to the study by Miller et al [19], the research should be extended to older adopted children in comparison to the sample observed in our research and the interval passed after the adoption should also be determined.

Regarding the children's socio-emotional deficiencies and their sometimes-endangered development, more effective and targeted measures are necessary to prevent later socio-emotional deficiencies [20]. Children have the right to health; healthy lifestyle and we always have to strive for creating optimal circumstances.

Because of the sensitivity of this topic, some limitations should be mentioned. Some of these limitations came up from the parents' side, such as their standoffish behavior, fear from possible negative feedback, and some of them came from the side of the service system, for example because of the protection of data related to the adoption. Some of the visited families did not undertake the 
interview because of prejudice and stigmatization. These families are usually closed, since they had experienced serious events also before the adoption, and they had to experience the social projection as a prejudice that they are unable to meet the social expectations, the social reproduction.

\section{REFERENCES}

[1] Online Available: http://www.ksh.hu/docs/hun/xstadat/xsta dat_eves/i_fsg004.html

[2] Zs. BOGÁR: Attachment in adoptive families, Family, Child, Youth, Vol. 8, No. 6, 52-57, 1999

[3] Zs. BOGÁR: Psychology of adoption, Branch Foundation, Debrecen, 2011

[4] M. NEMÉNYI, J. TAKÁCS: Adoption and discrimination in Hungary, Chance, Vol. /No.2, 67-96, 2015

[5] Methodological Publications II.: Methodological Child Protection Service of the Municipality of Budapest, Ministry of Human Resources, 2012. Online Available: http://mek.oszk.hu/11400/11415/11415.pdf

[6] van IJzendoorn MH, Juffer F., Duyvesteyn MG. Breaking the intergenerational cycle of insecure attachment? A review of the effects of attachment -based interventions on maternal sensitivity and infant security, Journal of Child Psychology and Psychiatry, Vol. 36, No. 2, 225-248., 1995

[7] E. BAGDY: Family socialization and personality disorders, Revisions, 1997

[8] E. NYITRA: The power of touch, Kulcslyuk Publisher, Budapest, 2011

[9] A. ZSOLNAI: Attachment and parenting, Eötvös József Book and newspaper publisher, Budapest, 2001

[10] K. MÉSZÁROS, G. MOLNÁR, N. RÓZSAHEGYI: Let's talk about it!, Budapest, Branch Foundation, 2013

[11] J. RANSCHBURG: Love, morality, autonomy, Thought Publisher, Budapest, 1993
[12] Sz. E. SCHLEIPERNÉ: Developmental psychology, Comenius Instructor és Publisher Bt., Pécs, 2007

[13] Johnson D. E. Adoption and the effect on children's development, Early Human Development, Vol. 68, 39-54, 2002

[14] Health Visitor's Training Journal Vol. XXV, No. 4, 2015

[15] Online Available: https://net.jogtar.hu/jogszabaly?docid=a0 400049.esc. 49/2004. (V. 21.) Ministry of Health, Social and Family Affairs Decree No. 49/2004. (V. 21.) on the Regional Midwife and Health Visitor Service

[16] P. HORVÁTH, A. SÁNDOR: The Adoption of Children with Special Needs in Hungary, Fogyatékosság és társadalom, Special issue, 55-63, 2018

[17] O. KERESZTES-TAKÁCS, Nguyen L. L. A. Stereotypes of adoptive and interethnic adoptive families in Hungary, Employee Psychology, Vol.18, No. 9, 7-27, 2018

[18] A. BATKI: The impact of early institutional care on emotion regulation: studying the play narratives of post-institutionalized and early adopted children, Early Child Development and Care, Vol. 188, 1801-1815, 2018

[19] Miller L., Chan W., Tirella L., Perrin E. Outcomes of children adopted from Eastern Europe, International Journal of Behavioral Development, Vol. 33, No. 4, 289-298, 2009

[20] Barone L., Ozturk Y., Lionetti F., The key role of positive parenting and children's temperament in post institutionalized children's socio - emotional adjustment after adoption placement. A RCT study, Wiley, 2019

[21] N. SCHEURING, E. PAPP, I., DANIS, T. NÉMETH, A. CZINNER: Background and diagnositic issues of regulation disorders in babyhood and infancy. Pediatrician training, Diagnostics Vol. X, No. 5, 13-19, 2011

[22] É. I. URBÁN: The influence of the environment on the development and stabilization of anxiety, New pedagogical review 57. évf. 1. sz. 70-89, 2007

[23] A. RUCSKA, J. LAKATOS, A. PERGE, E. KISS-TÓTH: Can they help? Prejudices and stereotypes against health care professionals with Roma origin, Social Pedagogy, International peer-reviewed journal, 2018:12, pp. 72-96, 24 p. 2018 